\title{
The relationship between a physician incentive plan and departmental performance in a Taiwan hospital
}

\author{
Nai-Yng Liu ${ }^{1}$, Hsuan-Lien $\mathrm{Chu}^{2}{ }^{2}$ Chiu-Chuo Liao ${ }^{3}$ \\ 1. Department of Accounting, College of Management, National Taiwan University, Taipei, Taiwan. 2. Department of \\ Accounting, College of Commerce, National Taipei University, Taipei, Taiwan. 3. Business Analysis Section, Shin Kong Wu \\ Ho-Su Memorial Hospital, Taipei, Taiwan
}

Correspondence: Nai-Yng Liu. Address: Department of Accounting, College of Management, National Taiwan University, Taipei, Taiwan. E-mail: naiyng@gmail.com

Received: February 6, 2013

Accepted: March 14, 2013

Online Published: March 24, 2013

DOI : 10.5430/jha.v2n3p79

URL: http://dx.doi.org/10.5430/jha.v2n3p79

\begin{abstract}
The objective of this study is to investigate the influence of a physician incentive plan based upon treatment of patients in a large private non-for-profit hospital in Taiwan. We examine the relationship between physicians' bonuses and departmental performance to assess the impact of the physician incentive plan in the case hospital. The multiple regression models are used to examine the relationship between physicians' bonuses and departmental profitability. In addition, we use Data Envelopment Analysis (DEA) model to measure the operational efficiency of each department in the case hospital. Then, a multi-factor Tobit model is used to examine the relationship between physicians' bonuses and departmental efficiency. The results indicate that physicians' bonuses in the case hospital are negatively correlated with departmental profitability and efficiency. That is, the performance measurement of current incentive plan may not be appropriate and it does not induce physicians to increase departmental profitability and improve efficiency. Our results suggest that the incentive plan is flawed and might fail to hold physicians accountable for improving departmental performance in the case hospital.
\end{abstract}

\section{Key words}

Incentive plan, Departmental profitability, Departmental operating efficiency

\section{I ntroduction}

The choice of measurement in the incentive scheme is the key factor to efficiently implement incentive plan, because the form of the optimal contract and the efficiency of this contract depend on the relationship between the performance measures used and the principal's objective. However, choosing appropriate measurement and designing an efficient incentive scheme that fully reflects physicians' contributions to a hospital's performance involves multiple factors.

In recent years, with the shifting tides of economic and regulatory pressures, hospitals have to be run like a business enterprise, finding ways to increase efficiency reduces the costs and eliminate waste ${ }^{[1]}$. In 2010 the Bureau of National Health Insurance (BNHI) in Taiwan introduced the Diagnosis-Related Group (DRG) payment scheme that control 
enormous national health expenditure. Therefore, hospital owners under this scheme are encouraged to minimize cost per case in order to maximize hospital net income ${ }^{[2]}$. The DRG scheme makes the economic viability of hospital much more dependent on its ability to influence either the hospital revenues or costs ${ }^{[3]}$.

A number of previous studies ${ }^{[4-7]}$ focused on specific cases to understand the relationship between a physician incentive plan and a hospital's performance and its impact on patients; or they used descriptive statistics to assess the effects of a physician incentive plan, and few empirical studies on the appropriateness of such plans ${ }^{[8]}$. However, there are few empirical studies investigated the impact of a specific incentive plan on hospital departmental performance.

In an attempt to bridge this research gap, the objective of this study is to investigate the impact of quantity based physician incentive plan in a private non-for-profit hospital in Taiwan by examining the relationships between physicians' bonuses and hospital departmental performance.

This study contributes to the literature by providing empirical evidence with the influence of physician incentive plans in the healthcare industry. It also provides useful insights for hospital executives concerning the potential pitfalls to be aware of when designing physician incentive plans.

The remainder of this study is structured as follows. In Section 2, we describe the research site. Section 3 contains a review of related literature and presents the hypothesis tested in this study. We explain the research design in Section 4, and present our empirical results in Section 5. Then, in Section 6, we summarize our conclusions, and discuss the limitations of the present study, and consider future research directions in Section 7.

Table 1. Physician fee charged Criteria

\begin{tabular}{|c|c|c|}
\hline Items & Details & Pre-determined percentage \\
\hline \multirow{3}{*}{ Outpatient Fee } & 1.Regular & 140 NT dollars/ per time \\
\hline & 2 Psychiatric & 200 NT dollar/ per time \\
\hline & 3.Emergency & $16 \%$ of total revenue in Emergency Department \\
\hline \multirow{4}{*}{ Diagnosis Fees } & 1.Regular & 273 NT dollar/ per time \\
\hline & 2.Psychiatric & 218 NT dollar/ per time \\
\hline & 3.Emergency & 612 NT dollar/ per time \\
\hline & 4 Nursery & 273 NT dollar/ per time \\
\hline Consultation Fee & & 218 NT dollar/ per time \\
\hline \multirow{2}{*}{ Examination Fee } & $\begin{array}{l}\text { 1. Invasive (operating, diagnosing and } \\
\text { treating by physician.) }\end{array}$ & $35 \%$ \\
\hline & $\begin{array}{l}\text { 2. Non-invasive (operating, diagnosing and } \\
\text { treating by physician.) }\end{array}$ & $25 \%$ \\
\hline Biopsy Examination & & $35 \%$ \\
\hline $\mathrm{X}$-ray Examination & & $20 \%$ \\
\hline Surgical Fee & & $60 \%$ \\
\hline \multirow{2}{*}{ Obstetrics } & 1.Nornal spontaneous delivery & 3782 NT dollar/ per person \\
\hline & 2.Cesarean & 4452 NT dollar/ per person \\
\hline \multirow{3}{*}{ Hemodialysis } & 1.Nephrology & 270 NT dollar/ per time \\
\hline & 2.Pediatrics & 300NT dollar/ per time \\
\hline & 3.Emergency & 270 NT dollar/ per time \\
\hline Medical Certificate & & $60 \%$ \\
\hline
\end{tabular}

Abbreviation monetary measurement unit of New Taiwan Dollar. One U.S. dollar is equivalent to roughly 29.26 New Taiwanese Dollars. 


\section{The research site}

The research site is a private non-for-profit hospital that was founded in 1992. Currently, the hospital has 35 medical departments and approximately 1,000 employees (including 426 physicians and 546 ancillary staff). Approximately 4,400 outpatients are treated per day and have roughly 920 beds; the average occupancy rate is $84 \%$ and the average length of stay is 11.5 days.

Under pressure from the National Health Insurance (NHI) scheme and increasing competition in the healthcare market, the hospital has implemented an incentive program to motivate physicians in order to improve the hospital's performance. For staff physicians in the case hospital, their monthly income is not based on a fixed salary, but wholly based on the incentive program. For each physician, the physician fee is linked to his/her contribution, the value of which is based on a percentage of the fees charged for diagnostic, laboratory, and other medical services that the physician provides. The pre-determined percentage depends on the difficulty or complexity of the medical service provided. Details of the pre-determined percentage in the case hospital are shown in the Table 1.

NT is the abbreviation monetary measurement unit of New Taiwan Dollar. One U.S. dollar is equivalent to roughly 29.26 New Taiwanese Dollars.

\section{Literature review and hypothesis development}

The DRG scheme (The Diagnosis Related Group (DRG) scheme classifies patient cases. Under the scheme, homogeneous hospital services are assigned a binding price ${ }^{[9]}$, and the reimbursement rate per case is set prospectively for each DRG category.) uses cost-relevant medical criteria, such as patient diagnoses and the procedures performed on patients, to classify hospital services. Hence, the reimbursement rate per service is set prospectively for each DRG category ${ }^{[9,10]}$. Under the fixed price DRG scheme, hospitals face greater financial pressure, and it has been suggested that the involvement of physicians in the management of medical resources becomes a critical issue to hospitals ${ }^{[11]}$. However, most clinical resource consumption is controlled primarily by physicians, not hospital administrators But, most physicians regard hospitals as workplaces that provide medical services ${ }^{[12]}$. They do not give priority to increasing profitability, reducing costs and improving efficiency, so there is often conflict between physicians and hospital owners, while hospitals increasing face fix-priced reimbursement ${ }^{[13]}$.

Several studies investigated the relationship between financial incentive and physicians' behaviors. Fairbrother et al. ${ }^{[14]}$ found that population-based cash bonuses were powerful motivator to increase overall immunization coverage significantly. In addition, Hickson et al. ${ }^{[15]}$ showed that fee for service physicians tended to deliver more medical service than physicians who paid by salary. Meanwhile, hospitals in United States use financial incentives to bond physicians to the hospitals' interests, and thereby reduce medical costs and improve the quality of care. Such schemes also increase physicians' productivity and efficiency ${ }^{[16]}$.

More recently, Pauly and Redisch ${ }^{[12]}$ who observed that physicians reduce the use of high cost medical procedures and use medical resources more efficiently when their salaries are linked the hospital's financial performance. Goes and Zhan ${ }^{[13]}$ also concluded that costs can be reduced significantly when physicians' financial interests are linked to a hospital's objectives.

However, Wee et al. ${ }^{[17]}$ showed that physicians who had incentives based on productivity lead physicians to see more patients and spend less time on form of prevention, particular time-consuming procedures, and hence decrease health quality improvement and cause more health expenditure in the future. In addition, Lo $^{[18]}$ found that financial incentives designed specifically for obstetricians do not reduce the cesarean section rate, which use more medical resource. Thus, how to motivate physicians to work in a way that is consistent with the objectives of the hospital owners is an important managerial issue. 
Kepes et al. ${ }^{[19]}$ highlighted the following important aspect of incentive plans. If the principal uses one dimension to measure an agent's performance, it will not reflect the worker's real effort appropriately. It may lead to dysfunctional behavior among employees and thus impact corporate productivity. Baker ${ }^{[20]}$ also point out that performance measurement, choosing which quantity to use in an incentive contract would cause employees to "game" the performance measure; for example, employees might take actions that increase payouts from the incentive contract without improve actual performance.

Therefore, in this study, we sought to investigate the relationship between physicians' cash bonuses and departmental performance; we assume that current incentive measurement in the case hospital is potentially inadequate. This incentive program might fail to hold physicians accountable for departmental performance, because such program will not encourage physicians to increase profit and improve efficiency. This leads to our hypothesis, which addresses the relationship between bonuses and physician performance.

Hypothesis: There should be a negative correlation between the departmental performance and the cash bonuses physicians receive.

\section{Research design}

\subsection{Sample selection and data resource}

Our objective is to assess the influence of a physician incentive plan in the case hospital by investigating the relationship between physicians' bonuses and departmental performance. The case hospital provided semi-annual financial data, details of bonuses, and related information for all departments for the period June 2007 to June 2009.

\subsection{Research design and variable measurement}

According to the literature ${ }^{[21,22]}$, several methods can be used to evaluate an organization's performance. Generally, the methods can be divided into those based on financial performance and those based on operational efficiency. Therefore, based on previous studies ${ }^{[23-27]}$ we use the financial performance and operational efficiency to measure departmental performance. A multi-regression model and the Tobit model are used to 1) investigate the relationship between bonuses and departmental performance; and 2) assess the influence of the incentive plan for physicians in the case hospital.

Meanwhile, according to a number of studies ${ }^{[28,29]}$ has found that there is a short lag between employees' actions and future financial performance. Hence, to capture the economic impact of the physicians' incentive scheme, we use the lead-lag relation to examine the effect of physicians' bonuses on the departmental performance.

\subsection{The impact of physicians' bonuses on departmental profitability}

Multi-regression is used to analyze whether there is a significant relationship between physicians' bonuses and a department's financial performance. Following previous studies ${ }^{[30]}$, we use the profit ratio (net revenue - direct cost/net revenue) as a dependent variable.

The profit ratio, which represents an organization's financial performance, can be easily understood by managers and outsiders like investors. Organizations can obtain this financial information without incurring high costs. In this study, we only consider direct costs because most indirect costs are allocated arbitrarily by the hospital's accounting department. Therefore, including indirect costs in evaluations of departmental performance might distort the real contributions that physicians make to a department.

\subsubsection{Definition of control variables}

In addition to physicians' bonuses, a number of other factors can influence departmental performance. 


\section{Department size}

Larger hospitals have more resources than smaller ones and therefore perform better. Serraqueiro and Nunes ${ }^{[31]}$ found that there is a positive relation between the size of an organization and its financial performance. In this study, we follow prior studies ${ }^{[32]}$ and use net revenue to represent a department's size and expect that a department's size and performance have a positive relation.

\section{Mortality rate}

The quality of care provided by a hospital will influence people's willingness to visit the hospital for treatment; thus, the better the quality of care, the more patients the hospital will treat ${ }^{[33]}$. Bazzoli et al. ${ }^{[23]}$ found that there is a positive relation between a hospital's financial performance and the quality of care. Clement et al. ${ }^{[34]}$ used the mortality rate as a proxy for quality of care and noted that a hospital's mortality rate decreases as the quality of care it provides increases. Therefore, in our research, we use each department's mortality rate to measure departmental quality, and expect that there will be a negative correlation between the mortality rate and departmental performance.

\section{Patient severity}

Since hospitals that treat a large number of severe patients need more medical resources, their performance may be worse than that of hospitals whose patient management category (PMC) severity scale is lower. Previous studies ${ }^{[13,35]}$ used the case mix index (CMI) to measure the degree of patient severity in each department; therefore, we use CMI as a proxy for patient severity in each department. We anticipate that there will be a negative correlation between CMI and a department's performance.

\section{Number of outpatient visits}

Departments that have more outpatient visits generate more revenue than those with fewer such visits, so their productivity should be higher. Chu et al. ${ }^{[27]}$ used the number of outpatient visits to measure each department's productivity. We adopt Chu et al.'s approach in this study, and anticipate that number of outpatient visits will have a positive relationship with departmental performance.

\section{Average length of stay}

The longer that patients stay in hospital, the greater will be the amount of medical resources required to treat them ${ }^{[36]}$. We expect that there is a negative relationship between the average length of stay and departmental performance.

\section{Number of operations}

When hospitals perform surgical procedures, they incurred the costs of the operations, as well as the cost of constructing operating theaters ${ }^{[37]}$. This may drain a hospital's resources and have a serious impact on its performance. Following prior studies ${ }^{[38]}$, we use the number of operations to measure the resources that each department consumes, and expect that a negative relationship exists between the number of surgical procedures and departmental performance.

\section{Physician seniority}

Harvey et al. ${ }^{[39]}$ found that, when dealing with emergency patients, senior doctors can reduce patients' waiting times and the length of stay in emergency rooms (ER) After controlling for patient severity, Kauvar et al. ${ }^{[40]}$ compared the operating times of senior and junior surgeons, and found that senior surgeons require much less time. Chu et al. ${ }^{[4]}$ also concluded that senior physicians use medical resources more efficiently. Therefore, we anticipate that a department's performance is related to the number of senior physicians in the department.

The above discussion can be summarized by the following regression model:

Profit ratio $t=\alpha+\beta 1$ bonuses $t-1+\beta 2$ department size $t+\beta 3$ mortality rate $t+\beta 4$ patient severity $t+\beta 5$ number of outpatient visits $t+\beta 6$ average length of stay $t+\beta 7$ number of operations $t+\beta 8$ physician seniority $t$ 
Where

Profit ratio $=$ Net revenue minus direct costs divided by net revenue in each department.

Bonuses $=$ Logarithmic cash bonuses paid to doctors in each department.

Department size $=$ Logarithmic net revenue of each department.

Mortality rate $=$ Total number of deaths divided by the total number of discharged patients.

Patient severity $=$ Case mix index of each department.

Number of outpatient visits $=$ Total number of outpatients treated by each department.

Average length of stay $=$ Total number of patient days divided by total number of inpatients treated by each department.

Number of operations $=$ Total number of operations performed in each department.

Physician seniority $=$ Total number of years a physician has served as an attending physician up to the first month of the period covered by this study, including periods served in other hospitals.

\subsection{The I mpact of physicians' bonuses on departments' operating efficiency}

We use efficiency scores calculated by the data envelopment analysis (DEA) model to evaluate each department's operating efficiency. DEA model is a non-parametric frontier estimation method to evaluate the efficiency. The advantage of the DEA model is that the DEA model can deal with multi-input and multi-output variables at the same time. In addition, the DEA model can use both financial data and non-financial data as variable to measure the relative efficiency performance of each department. The goal of most hospitals is multiple and complex; therefore, DEA model can provide hospital staffs as useful and low cost tool to evaluate health care service performance ${ }^{[41,42]}$. Previous studies ${ }^{[25,26]}$ used the DEA model to measure hospital efficiency. We use the model to measure departmental efficiency and examine the relationship between physicians' bonuses and departmental efficiency.

\subsubsection{Data envelopment analysis model}

The DEA model in this study measures the efficiency of each department relative to the performance of other departments in the case hospital.

We model the departments in the case hospital as multi-input, multi-output Decision Making Units (DMU) that attempt to minimize given inputs to achieve the same level of output. The input measure of efficiency $(\Phi)$ can be evaluated for any observation $j$. We use " $o$ " to denote a focal department whose efficiency score is computed as the solution to the linear programming problem as follows:

$$
\begin{gathered}
\min z \varphi \\
\text { subject to } \\
y_{g m} \leq \sum_{j=1}^{j} z_{j} y_{j m} \\
\sum_{J=1} z_{j} x_{j n} \leq \varphi x_{o n} \\
\varphi, z_{j} \geq 0 \\
m=1,2 \ldots ., M \\
n=1,2 \ldots ., N \\
j=1,2 \ldots ., \quad J
\end{gathered}
$$


Here, $z$ is an intensity or activity variable; and $X_{j n}, Y_{j m}$ are the respective outputs and inputs of the $j$ the department. Equation (2) evaluates a department's performance in terms of its ability to minimize its inputs subject to the constraints imposed by the best observed practices. If the department can make cutbacks, its optimal $\varphi^{*}$ is equal to 1 ; otherwise, its optimal $\varphi^{*}$ is less than 1 . The DEA model makes the assumption of constant returns to scale. Banker et al. ${ }^{[43]}$ proposed an extension of the model to account for cases of variable returns to scales by adding the constraint $\sum_{j=1}^{j} z_{j}=1$ to Equation (2). As the implication of efficiency will vary under different assumptions of returns to scale, we begin by investigating the kinds of returns to scale that provide the best explanation for our data. To this end, we use DEA-based statistical tests, which have been used to evaluate returns to scale for software development projects and software maintenance projects.

\subsubsection{Selecting input and output variables}

For each observation in the dataset, two output variables (number of discharges and number of outpatient visits) and five input variables (number of physicians, number of ancillary staff, material, capital costs, and operating costs) were constructed in the DEA model, based on prior literature ${ }^{[4,27]}$.

\subsubsection{Tobit model}

Since efficiency scores computed by the DEA model are censored at 1, an Original Least Square (OLS) estimate would produce biased and inconsistent parameter estimates ${ }^{[4]}$. Tobit analysis assumes that a number of dependent variable values will be clustered at a limiting value. For this reason, we use the Tobit model to determine whether there is a significant relation between physicians' bonuses and departmental efficiency.

We use the DEA efficiency score as the dependent variable and physicians' bonuses as the independent variable. The other control variables are the same as those in Equation (1).

Efficiency Scores $t=\alpha+\beta 1$ bonuses $t-1+\beta 2$ department size $t+\beta 3$ mortality rate $t+\beta 4$ patient severity $t+\beta 5$ number of outpatient visits $t+\beta 6$ average length of stay $t+\beta 7$ number of operations $t+\beta 8$ physician seniority $t$

Efficiency score $=$ The efficiency score computed by Equation (2) under the assumption that the returns to scale are appropriate.

\section{Empirical results}

\subsection{Descriptive statistics}

The descriptive statistics of the independent variables in the multiple regression models are presented in Table 2.

\subsection{The I mpact of physicians' bonuses on departmental profitability}

Table 3 shows the effect of physicians' bonuses on the departmental profit ratio of the case hospital. Multicollinearity was not considered a significant problem because the variance inflation factors (VIFs) for all variables were less than $10^{[45]}$. The hypothesis of homoscedasticity is rejected. As a result, we use White's covariance matrix estimator as the OLS estimator to avoid inconsistent and biased estimates ${ }^{[44]}$. 
The coefficient of bonuses in Table 3 is negative and significant $(t=-1.73, p<0.1)$. The results indicate that departmental profitability decreases as physicians' bonuses increase. There are two possible explanations for this phenomenon. First, the incentive plan might not motivate physicians to work harder and generate revenue for their department; therefore, the hospital's net revenue decreases. Second, the incentive plan only emphasizes the quantity of medical services that physicians provide. As a result, physicians are not concerned about reducing unnecessary medical resources. These possible explanations may help us interpret the above results.

Table 2. Descriptive Statistics of the Independent Variables $(\mathrm{N}=122)$

\begin{tabular}{lllll}
\hline Variables & Mean & Std. Dev. & Min & Max \\
\hline Bonuses & 16.115 & 0.781 & 14.384 & 17.521 \\
Department size & 17.852 & 0.800 & 15.955 & 19.730 \\
Mortality rate & 0.026 & 0.041 & 0 & 0.19 \\
Patient severity & 1.297 & 0.859 & 0.44 & 5.2 \\
Number of outpatient visits & $23,267.83$ & $19,743.16$ & 1,099 & 90,657 \\
Average length of stay & 10.58 & 10.895 & 2.8 & 67.3 \\
Number of operations & 522.172 & 713.905 & 0 & 2,738 \\
Physician seniority & 13.211 & 4.333 & 4 & 23.5 \\
\hline
\end{tabular}

With regard to the results for the control variables, consistent with our expectations, departmental profitability increases as the mortality rate decreases $(t=-4.16, p<0.01)$. Also, number of operations is positively and significantly related to departmental profitability $(t=3.29, p<0.01)$, suggesting that, in general, the financial benefits of performing operations are greater than costs of performing them. Finally, physician seniority has a negative and significant correlation with departmental profitability $(t=-2.89, p<0.01)$, which means that physician seniority negatively affect a department's performance.

Table 3. The Impact of Physicians' Bonuses on Departmental Profitability ( $=122$ )

\begin{tabular}{llll}
\hline Variables & Expected Sign & Coefficient & $t$-value \\
\hline Constant & $?$ & 0.9575 & $2.8^{* * *}$ \\
Bonuses & $?$ & -0.0302 & $-1.73^{*}$ \\
Department size & + & 0.0148 & 0.68 \\
Mortality rate & - & -1.1385 & $-4.16^{* * *}$ \\
Patient severity & - & -0.0075 & -0.58 \\
Number of outpatient visits & + & $-8.62 \mathrm{E}-07$ & -1.14 \\
Average length of stay & - & -0.0005 & -0.47 \\
Number of operations & - & $5.06 \mathrm{E}-05$ & $3.29^{* * *}$ \\
Physician seniority & + & -0.009637 & $-2.89^{* * *}$ \\
R-squared $=0.4254$ & & & \\
\hline${ }^{*}<0.1 ; * * p<0.05 ; * * *<0.01$ & & &
\end{tabular}




\subsection{The I mpact of physicians' bonuses on departmental operating efficiency}

In DEA analysis, the implications about efficiency will be different under different assumptions of returns to scale. We use DEA-based statistical tests ${ }^{[43]}$ to determine the return to scale that provides the best explanation for our data. The results of statistical tests suggest that the efficiency scores in this study should be computed under the assumption of variable returns to scale (detailed statistics are not reported here).

As the DEA efficiency score is a number between zero and one, we cannot use OLS to estimate the relations between the variables. Instead, we adopt Tobit regression to assess the effects of physicians' bonuses on departmental efficiency. The results are detailed in Table 4 . The coefficient associated with bonuses is negative but not significant. It suggests that the incentive plan may not encourage physicians to help improve departmental efficiency. With regard to the results of the control variables, department size is negatively related to departmental efficiency $(t=-2.74, p<0.01)$. It indicates that the smaller the department, the better its efficiency. The number of outpatient visits is positively and significantly related to departmental efficiency $(t=4.49, p<0.01)$.

Table 4. The Impact of Physicians' Bonuses on Departmental Operating Efficiency ( $\mathrm{N}=122)$

\begin{tabular}{|c|c|c|c|}
\hline Variables & Expected Sign & Coefficient & $t$-value \\
\hline Constant & $?$ & 0.79 & $10.17 * * *$ \\
\hline Bonuses & $?$ & $-2.46 \mathrm{E}-09$ & -0.87 \\
\hline Department size & + & $-1.64 \mathrm{E}-09$ & $-2.74 * * *$ \\
\hline Mortality rate & - & $-6.39 \mathrm{E}-01$ & -1.17 \\
\hline Patient severity & - & $-4.60 \mathrm{E}-02$ & -1.58 \\
\hline Number of outpatient visits & + & $8.45 \mathrm{E}-06$ & $4.49 * * *$ \\
\hline Average length of stay & - & $1.91 \mathrm{E}-03$ & 0.85 \\
\hline Number of operations & - & $-2.02 \mathrm{E}-06$ & -0.07 \\
\hline Physician seniority & + & $-1.99 \mathrm{E}-03$ & -0.3 \\
\hline
\end{tabular}

${ }^{*} p<0.1 ;{ }^{* *} p<0.05 ;{ }^{* *} p<0.01$

\subsection{Additional sensitivity tests}

To assess the robustness of our results, we conducted the following sensitivity tests.

\subsubsection{The impact of physicians' bonuses on physician productivity}

As a proxy for departmental performance, we use physician productivity instead of the profit ratio and efficiency to test the robustness of our results. Specifically, we use net revenues divided by the number of physicians to represent employee productivity.

From the results (not tabulated), we observe that bonuses are negatively and significantly related to employee productivity. The findings are consistent with our earlier assertion that the measurement of case hospital's current incentive scheme is not appropriate, and they support our hypothesis that bonuses are not associated with departmental performance. In other words, the current incentive plan does not motivate physicians to improve their productivity. 


\subsubsection{The I mpact of outpatient visits}

We did not include the number of outpatient visits as part of the output because it is also used as independent variable in the Tobit regression model. The results (not reported here) are similar to our earlier findings, and show that the incentive plan is not appropriate for the case hospital. Here, physicians' bonuses are significantly and negatively related to departmental efficiency.

\section{Conclusions and implications}

We have investigated the relationships between physicians' bonuses and departmental performance to assess the impact of a physician incentive plan in private non-for-profit hospital in Taiwan. In the following, we consider several important findings of our research.

First, we find that bonuses are negatively and significantly related to departmental profitability. This suggests that the current incentive plan does not encourage physicians to increase profitability. Second, the relationship between departmental efficiency and bonuses is negative. Because the incentive scheme focuses on the number of medical services provided and the revenue generated, physicians might be motivated to prescribe unnecessary treatments because such behavior would increase their bonuses. Third, as a proxy for departmental performance, we use physician productivity instead of the profitability and efficiency to assess the robustness of our results. Similar to previous studies, we find there is negative relationship between physician productivity and bonuses.

A one-dimensional incentive plan based on the number of patients that physicians treat or the revenue generated might not encourage physicians to reduce the unnecessary medical consumption and improve the quality of care. At the same time, the current incentive plan might cause ethical problems for the case hospital. The asymmetry of information between physicians and patients might encourage physicians to only see patients who are not seriously ill because they are easier to treat than severe patients and they consume fewer resources. Moreover, an incentive plan based on the quantity of treatment might encourage physicians to see patients more often or perform unnecessary operations.

To avoid counterproductive effect and the possibility of ethical problem, the case hospital should devise a multi-dimensional incentive plan to replace the current one-dimensional plan. Also, the case hospital should check all medical procedures to assess whether any of them should be revised. If possible, standard procedures should be introduced and every physician should be required to follow them. In addition, non-financial incentives could be used to strengthen the hospital's relationships with its physicians. Scott found that incentive programs in Australia include financial and non-financial incentives to encourage physicians to work harder. Therefore, the case hospital could consider non-financial incentives, such as training and promotion, to improve each department's performance.

\section{Limitations and future research}

The present study has some limitations that we should acknowledge. First, our case study focused on a specific hospital. To what extent our results can be generalized to other hospitals is an issue that could be explored in a future work. Ideally, we should have data from more research sites to replicate our investigation. However, few hospitals are willing to share their confidential data in such detail; and this factor partly explains the lack of empirical studies in this area.

Second, our study covered a two and a half-year period. During the period, macro-economic factors and changes in the healthcare environment, such as an aging population and modifications to the national health insurance policy, might have huge impacts on the case hospital's performance and might alter the study's findings. 


\section{References}

[1] Ernst and Young. "Sailing into the wind: managing academic medical centers in difficult times". 2009.

[2] Donaldson, C. and J. Magnussen. "DRGs: The road to hospital efficiency." Health Policy. 1992; 21: 47-64. http://dx.doi.org/10.1016/0168-8510(92)90128-X

[3] Lambert, R. A. and D. Larcker. "The prospective payment system, hospital efficiency, and compensation contracts for senior level hospital administrators.” Journal of Accounting and Public Policy. 1995; 14: 1-31. http://dx.doi.org/10.1016/0278-4254(94)00022-S

[4] Chu, H.L., S.Z Liu, J. Romeis, C.L. Laung. "The initial effects of physician compensation programs in Taiwan Hospitals: Implications for Staff Model HMOs.” Health Care Managment Science. 2003; 6(1): 17-26. http://dx.doi.org/10.1023/A:1021956103175

[5] Shin, C.Z. Essays in Department of Health Care Organization Administration. (Master Dissertation, National Taiwan University). 2001.

[6] Song, P.C. Essays in Department of Adminstration. (Master Dissertation, Chang Gung University). 1999.

[7] Zhou, S.C. "The evaluation of physician performance and restructuring of physician fee system under case payment:a case study of digestive surgery." China Medical University, Department of Health Service Administration. 1998.

[8] Chen, P.Y. 2005. "The Effect of the New Financial Incentive Program of the Department of Health on Its Hospital Operation Performance and Quality of Medical Care.” Yuan Ze University, Department of Administration.

[9] Ernst, C., A. Szczesny. "Cost Accounting Implication of Surgical Learning In the DRG ERA- Data Evidence From A German Hospital.” Schmalebach Business Review. 2005; 57(2): 127-166.

[10] Dismuke, C.E., V. Sena. "Has DRG payment influenced the technical efficiency and productivity of diagnostic technologies in Portuguese Public hospital? An empirical analysis using parametric and non-parametric methods.” Health Care Management Science. 1999; 2(2): 107-116. PMid:10916607 http://dx.doi.org/10.1023/A:1019027509833

[11] Lehtonen, T. "DRG-based prospective pricing and case-mix accounting- Exploring the mechanisms of successful implementation. Management Accounting Research. 2007; 18: 367-395. http://dx.doi.org/10.1016/j.mar.2006.12.002

[12] Pauly, M., M. Redisch. "The not for profit hospital as a physicians' cooperative." American Economic Review. 1973; 63(1): 87-99.

[13] Goes, J.B., C.L. Zhan. “The Effects of Hospital-Physician Integration Strategies on Hospital Financial Performance.” Health Service Research. 1995; 30(4): 507-530. PMid:7591779

[14] Fairbrother, G., K. L. Hanson., S. Friedman., G. C. Butts. "The impact of physician bonuses, enchancedfees, and feedback on childhood immunization coverage rates.” American Journal of Public Health. 1999; 89: 171-175. PMid:9949744 http://dx.doi.org/10.2105/AJPH.89.2.171

[15] Hickson., G. B., W. A. Altermeier., J. M. Perrin. "Physician reimbursement by salary or fee for service: effect on physician practice behavior in a randomized prospective study." Pediatrics. 1987; 80(3): 344-350. PMid:3627885

[16] Davis, A. and C.T. Hardy. "New compensation model improves physician Productivity." Healthcare Financial Management. 1999; 1: 46-49.

[17] Wee., C.C., R. S. Phillips., H. R. Burstin., E. F. Cook., A. L. Puopolo., T. A. Brennan., J. S. Haas. "Influence of financial productivity incentives on the use of preventive care." The American Journal of Medicine. 2001; 110: 181-187. http://dx.doi.org/10.1016/S0002-9343(00)00692-6

[18] Lo., J. C. "Financial incentives do not always work-An example of cesarean sections in Taiwan." Health Policy. 2008; 88: 121-129. PMid:18436331 http://dx.doi.org/10.1016/j.healthpol.2008.02.013

[19] Kepes, S., J. Delery, N. Gupta. "Contingencies in the effects of pay range on organizational effectiveness." Personnel Psychology. 2009; 62(3): 497-531. http://dx.doi.org/10.1111/j.1744-6570.2009.01146.x

[20] Baker, G.P. "Incentive contracts and performance measurement.” Journal of Political Economy. 1992; 100(3): 598-614. http://dx.doi.org/10.1086/261831

[21] Hyer, N.L., U. Wemmerlöv, J.A. Morris. "Performance analysis of a focused hospital unit: the case of an integrated trauma center." Journal of Operations Mangement. 2009; 27(3): 203-219.

[22] Tseng, F.M., Y.J. Chiu., J.S., Chen. "Measuring business performance in the high-tech manufacturing industry: A case study of Taiwan's large size TFT-LCD panel companies.”Omega. 2009; 37(3): 686-697. http://dx.doi.org/10.1016/j.omega.2007.07.004

[23] Bazzoli, G.J, H.F Chen, M.Zhao and R.C. Lindrooth. "Hospital Financial Condition and the Quality of Patient Care.” Health Economics. 2008; 17(18): 977-995. PMid:18157911 http://dx.doi.org/10.1002/hec.1311 
[24] Ozcan, Y.A., M.J. McCue. “Development of a Financial Performance Index for Hospitals: DEA Approach.” The Journal of the Operational Research Society. 1996; 47(1): 18-26.

[25] Harrison, J.P., C. Sexton. "The Improving Efficiency Frontier of Religious Not-for-Profit Hospitals.” Nursing and Health Magazines. 2006; 84(1): 2-10.

[26] Biorn, E., T.P. Hagen, T. Iversen, J. Magnussen. "The Effect of Activity-Based Financing on Hospital Efficiency: A Panel Data Analysis of DEA efficiency score 1992-2000." Health Care Management Science. 2003; 6(4): 271-283. PMid:14686633 http://dx.doi.org/10.1023/A:1026212820367

[27] Chu, H.L., S.Z Liu, J. Romeis. "Does the Implementation of Responsibility Centers, Total Quality Management, and Physician Fee Programs Improve Hospital Efficiency? Evidences from Taiwan Hospitals.” Medical Care. 2002; 40(12): 1223-1237. PMid:12458304 http://dx.doi.org/10.1097/00005650-200212000-00009

[28] Ittner, C., D. Larcker. Are nonfinancial measures leading indicatorsof financial performance? An analysis of customer satisfaction. Journal of Accounting Research. 1998a; 205-238

[29] Banker, R. D., G. Potter, and D. Srinivasan. An empirical investigation of an incentive plan that includes nonfinancial performance measures. The Accounting Review. 2000; 75 (1): 65-92. http://dx.doi.org/10.2308/accr.2000.75.1.65

[30] Love, D., L. Revere, and K. Black. “A Current Look at the Key Performance Measures Considered Critical by Health Care Leaders" Journal of Health Care Finance. 2008; 34(3): 19-33. PMid:18468376

[31] Serragueiro, Z.S., P.M. Nunes. "Performance and Size: empirical evidence from Portuguese SMEs." Small Business Economic. 2008; 31(2): 195-217. http://dx.doi.org/10.1007/s11187-007-9092-8

[32] Devers, C.E., G. McNamara, R.M. Wiseman., M. Arrfelt. "Moving Closer to the Action: Examing Compensation Design Effect on Firm Risk.” Organization Science. 2008; 19(4): 548-566. http://dx.doi.org/10.1287/orsc.1070.0317

[33] Milutinovic, D., B. Brestivacki, and M. M. Cvejin. "Patients' satisfaction with nursing care as an indicator of quality of hospital service." HealthMED. 2010; 4(2): 461-468.

[34] Clement, J.P., V.G. Valdmanis, G.J. Bazzoli, M. Zhao, A. Chukmaitov. "Is more better? An analysis of hospital outcomes and efficiency with a DEA model of output congestion”. Health Care Management Science. 2008; 11(1): 67-77. PMid:18390169 http://dx.doi.org/10.1007/s10729-007-9025-8

[35] Chirikos, T.N. and A.M. Sear. "Measuring Hospital Efficiency: A Comparison of Two Approaches." Health Service Research. 2000; 34(6): 1389-1408. PMid:10654837

[36] Duckettr, S.J. and S.M. Kristofferson. “An Index of Hospital Performance.” Medical Care. 1978; 16(5): $400-407$. http://dx.doi.org/10.1097/00005650-197805000-00004

[37] Harison, E., E. Berghout. "The effect of information system of the performance of medical units: the case of operating rooms." European and Mediterranean Conference on Information Systems. 2008; 25-26: 1-14.

[38] Hu, J.L., Y.F. Huang. “Technical Efficiencies in Large Hospitals: A Managerial Perspective.” International Journal of Management. 2004; 21(4): 506-513.

[39] Harvey, M., M.A. Shaar, G. Cave, M. Wallace, P. Brydon. "Correlation of physician seniority with increased emergency department efficiency during a resident doctors' strike”. Journal of the New Zealand Medical Association. 2008; 121(1272): 59-68.

[40] Kauvar, D., A. Braswell, B. Brown, and M. Harnisch. "Influence of Resident and attending Surgeon Seniority on Operative Performance in Laparoscopic Cholecystectomy”. Journal of Surgical Research. 2006; 132(2): 159-163. PMid:16412471 http://dx.doi.org/10.1016/j.jss.2005.11.578

[41] Vassiloglou, M. and D. Giokas. "A study of the relative efficiency of bank branches: an application of data envelopment analysis." The Journal of the Operational Research Society. 1990; 41(7): 591-597.

[42] Liu, Z., X. Zhang and D. Yang. "The efficiency evaluation of out-of pocket healthcare expenditure in China: Data envelopment analysis-tobit analysis based panel data" Health MED. 2012; 6(12): 4244-4252.

[43] Banker, R.D. "Hypothesis tests using data envelopment analysis" The Journal of Productivity Analysis. 1996; 7(2-3): 275-282. http://dx.doi.org/10.1007/BF00157038

[44] Greene, W. H. 2008. Econometric Analysis (6th). NJ: Prentice Hall.

[45] Neter, J.W., W., M.H. Kutner, C.J. Nachtsheim, W. Wasserman. 1989. “Applied linear regression models” Boston MA: Irwin Book Team. 